\title{
Teaching Innovation And Use Of The ICT In The Teaching-Learning Process Within The New Framework Of The EHEA, By Means Of Moodle Platform
}

Adelaida Ciudad-Gómez, University of Extremadura, Spain

\begin{abstract}
The framework of the European Higher Education Area (EHEA) has turned the student into the main protagonist of the new educational scenario, and the teacher into the coordinator of teaching-learning process instead of transmitter of knowledge. In this new model of learning, the use of ICT is facilitating competency-based learning and the autonomous use of educational resources by the student. In view of this situation, e-learning platform Moodle gives teachers and students a tool that extends and improves the teaching-learning process, and that makes possible the creation of virtual subjects to develop a virtual-presence model which can favour the selflearning, the participation and the acquisition not only of specific skills in our discipline, but also of instrumental skills, personal and systemic. Therefore, the objective of this paper is to share our experience in relation with the virtual university and with the development of an education in Accounting supported by the Moodle platform and new ICTs, with their advantages and disadvantages, putting forward the global design that has been applied to the virtual subject and what technological tools have been considered relevant to achieve our educational aims.
\end{abstract}

Keywords: ICT; teaching-learning process; European Higher Education Area (EHEA); Moodle

\section{INTRODUCTION}

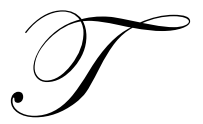

he framework of the European Higher Education Area (EHEA) has turned the student into the main protagonist of the new educational scenario. A system is being implemented based upon the necessary workload the student has to carry out in order to achieve the goals set. These are based upon the results of the learning and the skills he must acquire. On the other hand, the teacher becomes an orchestra director, the person ultimately in charge of the process at the start of the course, but he will assign responsibility to the student as the course goes on, in such away that at the end the teacher only does the work of an assessor.

This all meant that we will propose the need for ourselves to redesign our subjects and to modify our teaching-learning methodology, with the aim of achieving an improvement in the capacity of our teaching staff, making student learning active, inductive, cooperative and collaborative.

We are also convinced that the incorporation of Information and Communication Technologies (ICTs) into the teaching-learning process provide us with excellent possibilities, with one of its applications being the creation of virtual subjects that are complementary to the classroom teaching system, since as UNESCO points out (2008) they can assist students to acquire the necessary abilities in order to become:

- $\quad$ skilled in using information technologies;

- $\quad$ information searchers, analysers and evaluators;

- $\quad$ problem solvers and decision makers;

- $\quad$ creative and effective users of productivity tools;

- $\quad$ communicators, collaborators, publishers and producers; and 
- $\quad$ citizens who are informed, responsible and capable of contributing to society.

In this educational context and with the desire to improve, we decide to incorporate new technologies into our teaching-learning process, and we are proposing the creation of new virtual subjects, but with the precaution of the integration of the ICTs into the teaching-learning process being appropriate, because if not would could end up with something contrary to what is wanted.

In light of this challenge, the Virtual Campus of the University of Extremadura (CVUEx), has provided us with tools for extending and improving the Teaching-Learning processes through the e-learning Moodle platform, which have enabled us to develop a new virtual-classroom model. The aim of this is to assist a form of learning that is controlled and directed by the teacher and promote student participation, as well as support not only the specific skills of our discipline, but also instrumental, personal and systematic skills.

For all of these reasons, we aim to share our experience in the virtual university and the development of a form of teaching in Accountancy by means of classroom learning supported by the Moodle platform, with its advantages and inconveniences, making a presentation about the overall design applied in virtual subjects and dealing with the selection and management of those technological tools that have been considered to be pertinent in order to achieving our educational goals.

\section{DISTANCE HIGHER LEARNING AND THE VIRTUAL UNIVERSITY}

Distance learning has traditionally been compared to correspondence learning, but nowadays, thanks to new technologies, interaction and feedback are increasingly equated to classroom learning. As on-line teaching, virtual training, virtual education, e-learning training, distance collaborative learning, etc. arise, e-learning can become associated with the virtual campus concept in the university sphere.

Technological advances, in both hardware and software, have facilitated new forms of information processing and created new structures (hypertextual and hyper-media), which are not only going to complement the University, but are also going to transform it. When new technologies are incorporated into the university context, virtual classrooms emerge which, according to GISBERT and others ${ }^{1}$ (1997-1998, Page 32), "are the concept that is currently bring together the possibilities of teaching-learning based upon a communication system using computers".

But the use of computers and Internet in university teaching, as AREA points out (2000, Pages. 128-135) has gone through different levels, from the simple publication of the programme or material of the subject on a web page, to the creation and setting underway of a distance on-line training system, developed institutionally by one or several universities:

Table 1: Levels of integration and Internet use in university teaching

\begin{tabular}{|l|l|}
\hline \multicolumn{2}{|c|}{ Levels Of Integration And Internet Use In University Teaching } \\
\hline Level I & $\begin{array}{l}\text { Publishing Conventional Documents In HTML. } \\
\text { Publish the programme and/or the notes for the subject on the teacher's personal web page. }\end{array}$ \\
\hline Level II & $\begin{array}{l}\text { Preparation Of Electronic Or Tutorial Didactic Materials For The WWW } \\
\text { Prepare an electronic didactic material or tutorial programme so the students can study of the subject in an } \\
\text { autonomous way. }\end{array}$ \\
\hline Level III & $\begin{array}{l}\text { Design And Development Of Part-Time Attendance Online Courses. } \\
\text { Design and develop training courses or programmes that combine the offer of an online tutorial with classroom } \\
\text { meetings or sessions between the students and the teaching staff }\end{array}$ \\
\hline Level IV & $\begin{array}{l}\text { Virtual Education } \\
\text { Design and develop distance and virtual educational courses or programmes, supporting communication exclusively } \\
\text { between the teacher and students using data transmission networks. }\end{array}$ \\
\hline
\end{tabular}

Source: Área Moreira, M. (2000)

${ }^{1}$ Gisbert, J. and others (1997-1998): “Entornos virtuales de enseñanza y aprendizaje [Virtual teaching and learning environments]”, Cuadernos de documentación multimedia, 6-7 and 29-40. Cited in Cabero Almenara, J. (2002, Page 40) 
These level III or IV virtual contexts require a specific form of organisation, structuring and availability of the contents and the information to the students, in which two types of communication take place: asynchronic (not done in real time) and synchronic (in real time). The tools to be used may be electronic mail or forums in the case of asynchronic communication, and chat and audio-videoconferences for synchronic communication. Moreover, it is necessary for there to be an interface between the three participants in the data transmission training environment: the student, the teacher and the programme administrator.

As regards the teaching-learning modules, each one will have communication-partnership tools, shared applications tools, browsing and search tools, as well as elements for authenticating the subject in the system. The contents will possess a specific structure and design, which make it possible to present the same information in different ways and incorporate work software into the equipment, which the student can interact with, evaluate himself and access the complementary information available in the module or other servers. These assure us that by obligation these pass through the significant cores.

Learning management platforms are used in mass form in virtual university teaching, since they provide us with an integrated environment where all of the typical functions of the teaching-learning process are included, together with those services that are necessary for information and communication between users, in both synchronic and asynchronic forms.

One of these e-learning platforms is the Moodle, a piece of free software which, according to the statistics from its web site, had 45,669 registered servers that were located in 206 countries in February 2010, and on which $3,176,633$ courses were taught, with $32,391,831$ students and 1,214,278 teachers.

\section{THE MOODLE PLATFORM}

The Moodle (Modular Object-Oriented Dynamic Learning Environment) platform is an application that belongs to the group of LMS, Learning Management Systems, also known as the VLE, Virtual Learning Managements, that is to say, it is an application for creating and managing learning platforms.

This application is noted for its free nature, being simple to maintain and update, which practically does not require "maintenance" by the administrator, so it is easy to use for both teachers and students. There is a large community behind what is constantly improving and based upon problem solving, and both its design and development are based on the learning theory known as "social constructionist pedagogy", for which learning is especially effective when it is done by sharing it with others.

The structure of a virtual course using the Moodle will comprise four basic parts: Head, central column, left and right column and bottom of the page. The head contains the main bar with the name of the course, register information (with hyperlink to the personal profile) and a link to Exit the system; and just below the navigation bar, with the links in order to provide us with access to the different places of the course, the publish button and a dropdown menu which will enable us to change our role (Teacher, Non-editing teacher, Student).

The central column contains the particular elements of the course, mainly the links to the different resources and activities, and in turn it is divided into boxes or sections of contents, whose format will define the basic layout of the course. The virtual course will be able to contain sections as specified in its configuration form, being numbered from 1 upwards, other than the first one that is used for general elements. As regards its format, Moodle provides us with three possibilities which are: the social format, which enables us to apply a democratic methodology, where the exchange of experience and collaboration between partners prevails; the weekly format, useful when what is prioritised are temporary issues since this format enables us to plan our course in a fundamentally chronological way, assisting the student's organisation; and finally, the themed format, making it possible to structure the subject by topics, separately setting out information and resources.

As regards the resources and activities that the platform enables us to include, we could group these into three types, contents, communication and evaluation. The contents activities are focused on offering information to the student; the active subject is the teacher who performs the function of conveying the information. Most of these 
activities are found in the dropdown list called "Add resource", although there are activities not located here that could be perfectly well classified as "content activity" in some situations, such as for example, the Glossary activity, which will have a knowledge transfer function if this is exclusively prepared by the teacher.

Amongst the communication activities, which facilitate communication between students and the teacher between themselves, we find the forums and chat rooms, and lastly, amongst the evaluation activities that are not exclusively focused on assessing the student, but also this will be the consequence of is learning, making it possible for us to have interactive and collaborative student learning ${ }^{2}$, highlighting the questionnaires, the tasks, the Wikis, etc.

The blocks that the Moodle places at our disposal for the most suitable configuration of the course are located in both the left and right-hand columns. On the left we can see the following blocks: Persons, Activities, Search in the forums, Administration and Mt Courses; while in the right-hand column, if we click on the Activate publishing button, a block will appear that enables us to select new blocks to add to our course, amongst which we can choose: Recent activities, general search, Credit calculation, Timetables, RSS Channels, Course Description, Random Glossary Entry, Coming events, Feedback, HTML, Tags, Messages, Mentees, New Developments, Quiz Results or Users online. Finally, the bottom of the page of the course shows our authentication (name and surnames of the user) and a link to the help documents of the Moodle site.

\section{METHODOLOGY IN THE DESIGN OF OUR VIRTUAL PROPOSAL}

Our proposal for the creation of virtual subjects parallel to classroom teaching has been created within the Virtual Campus of the University of Extremadura (CVUEx), based upon the Moodle e-learning platform. These subjects are Financial Accounting II (Obligatory University course) and Public Accounting (optional), both relating to the Diploma course in Business Sciences taught at the Faculty of Business Studies and Tourism of the University of Extremadura (Spain), although in this work we will exclusively refer to Financial Accounting $I^{3}$, as both are developed in a similar way.

When it comes to designing our virtual subject we have drawn up certain approaches prior to the implementation of the virtual training action, both psycho-pedagogical where we have asked ourselves "What should we teach?, how to teach it? and what and how to assess?", and technological where we have analysed which technologies are best suited to our psyco-pedogogical approach.

As a complementary element to our design, when the course starts we assure ourselves that our students would normally be able to access Internet, and furthermore the preliminary knowledge that our students had in relation to the utilisation of the virtual university and the ICTs was compared using feedback. Basically two conclusions were observed from this; that the student is familiarised with the use of the virtual classroom and those most common resources and activities (forums, chat rooms, tasks, etc.) although more complex activities such as Wikis are unknown -and so if they were used in the end it was recommended to have preliminary sessions in the computer room- and on the other hand, that there were few students who had difficulties in habitually using Internet.

\footnotetext{
2 Ariza and Oliva (2000), in defining collaborative learning (CL) they state that "Etymologically speaking, collaborate (cum labore) means working with someone else, therefore, it carries a implicit intention, having common goals and another explicit one: "add value", that is, produce something new or different through collaboration. This is all very different from the simple exchange of information or indication of instructions, as could occur in any type of tutorial."

${ }^{3}$ General Objectives And/Or Specific Skills: Financial Accounting II is at the intermediate level of Accountancy, so for this reason, it deals with the fundaments of accountancy. It is necessary to go into further detail and intensify accounts knowledge, acquiring the most characteristic skills of the profession. We focus ourselves on:

a) Go into depth in the analysis, understanding, valuation and recording of the transactions related to the basic financing of the entities and organisations, own and external financing.

b) Know and understand those accounts fundaments related to external accountancy and the process of preparation and drawing up of the Annual Accounts.

c) In any introductory manner, know the technical principles and the basic process followed in the analysis and interpretation of the accounts information.

d) Introduce the student into the analysis of the accounts process in order to certify the quality of the synthesis.
} 
Having established the content of the subject, taking account of the skills and objectives pursued and the person we are targeting, and having decided on the teaching methods or techniques within the didactic design strategy stage, we moved on to carry out or put into practice our teaching activity and the creation of a virtual subject. This enabled us to combine the distance and the classroom methodologies, on the basis of the methodology proposed, the dialectical method in solving practical cases, and the heuristic method, in doing individual or group work.

The first decision as regards the design was to choose the structure of the central column of our virtual subject within the three existing formats, opting for the "themed" format, and each topic was basically structured into four modules. The first module includes the documents prepared by the teacher; the second the links to those net resources or documents that seem interesting to us; the activities to be done by the student in each topic are presented in the third module; and lastly, a forum for doubts.

When it comes to choosing the tools to be used on our course, we have based ourselves on their relevance for obtaining the didactic objectives that we are pursuing, that they are easy for both us and the students to manage, avoiding the use of the tool being converted into the important thing, and which enables us to check the results of the learning.

Initially, when our virtual signature was created, we used those contents resources or activities that enabled us to offer information to the student. Through the "labels" we have provided each "content section" with a format and with "publish a page of text", we have included the programme of the subject in the initial course contents section, used for general elements.

Our virtual course, in addition to the initial general section, contains as many contents sections as topics that the programme contains. In each one of these, through the "Link to a file" resource we have added theoretical and practical material about the subject that had been prepared beforehand by the teacher; and through the "Link to a web page" resource we have linked to videos and web pages related to the subject.

Amongst the tools incorporated into our classroom we have had the "glossary", which enables the student to have the possibility of including those definitions of general accounts terms commonly used in the subject, and where the teacher's role was that of correcting and assessing the contributions made by the students, placing them at everyone's disposal. This has a twofold use; on the one hand it has promoted the self-learning of the student when working on his contributions, and on the other hand, it has provided him with the possibility of clearing up doubts. We will also pointed out tools with greater difficulty such as the "Wikis", for which we have considered it appropriate to postpone them being used for coming academic courses.

In the same way, "tasks" of different types have been proposed for it, amongst which we have mainly opted for those of "On line text", "Offline activity" and "Advanced uploading of files" and also added self-assessment tests such as a "questionnaire" activity, enabling to student to find out his results in real time.

The tasks of the "Offline activity" type have been used so as to include the classroom character tests assessments done by the student outside the virtual subject and those of the "Online text" type in the solving of cases related to the subject. We propose analysis and reflection as to their viability or otherwise and, as the case may be, a proposal of a feasible solution in a reasoned way; and those of the "Advanced uploading of files" type, for the undertaking of work or solving cases.

In addition, and because it is very useful, each one of the sections has used the "forum" communication tools, a hugely socialising tool of great applicability, mainly used as a space for resolving doubts, for the presentation of the subject at the start of the course, as well as to report on issues such as the call for tests or their assessments.

In the same way, it has been useful for us to spark discussions about specific topics where the theoretical content or complementary information had been provided in advance, so as to request an information search about a topic and to be able to respond to future issues in the discussion, so as to work on approaches such as the group 
dynamic, to do case studies, or even as a rest area for the students, creating a forum exclusively for them (Forum for the student).

Before the management of the forums is implemented we propose "the preparation of the discussion", in which we have taken account of the fact that the objectives we are pursuing, the function of the teaching-learning discussion, scheduling of dates, forum type, whether assessable or not, minimum discussion rules that the student must abide by, or the need to delivery complementary material or not.

Finally, we have included the following blocks in the right-hand column of the subject: online users, html blocks for important information, agenda, messages and remote RSS channels. We must therefore point out that with our virtual subject proposal we have taken the first step towards the incorporation and utilisation of the ICTs in education, but our argument is for our virtual classrooms to enter into a process of continuous improvement, using the year-on-year experience to make the necessary adjustments, and which are increasingly used in the teachinglearning process as a complement to the classroom part, improving our skills and abilities.

For this reason, once the course has ended the aim is to carry out anonymous feedback surveys in order to evaluate the different aspects of the virtual subjects and of the teacher, which will enable us to apply adjustments of improvements for coming courses. This aim does not overlook improving skills and abilities for which we participate and coordinate a Training Project of a Didactic Innovation Group subsidised by the SOFD of the University of Extremadura (Spain), known as "Improvement of the teaching-learning process through the virtual platform and creation of a Guide to preparation of targeted work ", made up of a group of teachers involved in different disciplines, sharing a common interest in educational work.

\section{CONCLUSIONS}

The guidelines for the adaptation to EHEA point towards a design of the subjects based on learning goals and skills, affecting both the teaching-learning methodology and evaluation, moving on to interactivity, which is fundamental in the current process based upon the self-learning of the student.

All of these changes oblige us to shape ourselves to this new environment. One of the changes in our adaptation has been to incorporate the use of the new ICTs into our teaching-learning process, making the most of all their possible educators, amongst whose applications we highlight the creation of virtual subjects, which could provide a significant improvement in the classroom teaching system, even though it requires us to possess new skills and abilities that we sometimes do no master.

For the creation of our virtual subject we have used the Moodle online platform, a technological innovation which has enabled us to publish documents in any format (doc, xls, ppt, pdf, html, etc), administer discussion forums, linking to files, videos and web pages, crate groups of students, propose jobs and activities that can be assessed, using a common area in order for the students to send them, structure an agenda with key dates and tasks, be able to publish calls and notices, as well as carry out individual monitoring of access to the platform for each student.

When it comes to designing our virtual subject we have carried out certain preliminary approaches, both psycho-pedagogical and technological, first assuring ourselves that our students had the resources and knowledge necessary to be able to participate in the virtual university.

Having established the content of the subject, taking account of the skills and objectives pursued and the person we are targeting, and having decided on the teaching methods or techniques within the didactic design strategy stage, we moved on to put into practice our teaching activity and the implementation of a virtual subject. This enabled us to combine the distance and the classroom methodologies proposed, mixing together the dialectic method in resolving practical cases, with the heuristic method proposing the undertaking of individual or group work to the student. 
With our virtual subject proposal we have taken the first step towards the incorporation and utilisation of the ICTs in education, but our argument is for our virtual classrooms to enter into a process of continuous improvement, using the year-on-year experience to make the necessary adjustments, and which are increasingly used in the teaching-learning process as a complement to the classroom part, improving our skills and abilities.

Finally, as the next step we consider it essential to use our empirical study to assess the results and contributions that said educational innovation has actually meant in improving the quality of the teaching in our specific context.

\section{AUTHOR INFORMATION}

Adelaida Ciudad-Gómez: Degree in Business Administration by University of Sevilla. Associate Professor at Accounting Department. Faculty of Business Studies and Tourism of Cáceres. University of Extremadura (Spain). E-mail: adelaida@unex.es.

Research Interest: accounting, corporate governance

\section{REFERENCES}

1. Area Moreira, M. (2000): “Qué aporta Internet al cambio pedagógico en la educación superior”, publicado en PÉREZ, R. (coord.): "Redes multimedia y diseños virtuales”. Actas del III Congreso Internacional de Comunicación, Tecnología y Educación. Universidad de Oviedo. Available in: http://webpages.ull.es/users/manarea/Documentos/documento7.htm.

2. Ariza, A. and Oliva, S. (2000). Las nuevas tecnologías de la información y la comunicación y una propuesta para el trabajo colaborativo. Available in: http://www.c5.cl/ieinvestiga/actas/ribie2000/papers/405/

3. Cabero Almenara, J. (2002): "Universidad y sociedad de la información: la implantación de las nuevas tecnologías de la información y la comunicación". En "Materiales para la Enseñanza Universitaria" Núm. 3. Universidad de Extremadura. Instituto de Ciencias de la Educación. Badajoz. Págs. 29-55.

4. Cole, J and Foster, H. (2008): "Using Moodle (2nd Edition)". O'Reilly. United States of America. Available in: http://docs.moodle.org/en/Using_Moodle book.

5. Correa Gorospe, J.M. (2005). La integración de plataformas de e-learning en la docencia universitaria: Enseñanza, aprendizaje e investigación con Moodle en la formación inicial del profesorado, Revista Latinoamericana de Tecnología Educativa, 4 (1), 37-48. Available in: http://www.unex.es/didactica/RELATEC/sumario_4_1.htm.

6. Levy, Y. (2007): Comparing dropouts and persistence in e-learning courses. Computers \& Education, vol. 48(2), pp. 185-204.

7. Martínez Aldanondo, J. (2004). El papel del tutor en el aprendizaje virtual. Available in: http://www.uoc.edu/dt/20383/index.html

8. Mondéjar Jiménez, J.; Mondéjar Jiménez, J. A. and Vargas Vargas, M. (2006): "Implantación de la metodología e-learning en la docencia universitaria: una experiencia a través del proyecto Campus Virtual". Revista Latinoamericana de Tecnología Educativa, 5 (1), 59-71. Available in: http://campusvirtual.unex.es/cala/editio/

9. Petrova, K. (2007): Mobile learning as a mobile business application. International Journal of Innovation and Learning, vol. 4 (1), pp. 1-13.

10. UNESCO (2008): "Estándares de competencias en TIC para docentes". Available in: http://cst.unescoci.org/sites/projects/cst/default.aspx. 
NOTES 